\title{
SUPPURATIVE MENINGITIS IN THE NEWBORN DUE TO COLIFORM BACILLI
}

\author{
BY \\ K. J. RANDALL \\ Assistant Lecturer in Pathology, Guy's Hospital Medical School
}

(RECEIVED FOR PUBLICATION, FEBRUARY 11,1948 )

Although infrequent, suppurative meningitis in the first month of life is now more commonly recognized than formerly. Barron (1918), reviewing meningitis in infancy nearly thirty years ago, found only thirty-nine cases of the suppurative form reported in children under three months, nineteen of which were in the newborn. From this he concluded that suppurative meningitis is a rare disease at this age.

Cruickshank (1930), in a general survey of neonatal deaths, found that meningitis was responsible in thirty-three out of eight hundred cases, about 4 per cent. Flensborg (1942) was able to collect 140 reports from the literature of suppurative meningitis in infants under one month old. In his own series of 374 necropsies on newborn infants, he found three cases ( 0.8 per cent) of suppurative meningitis. Still more recently MacGregor (1946) has recorded the pathological findings in 618 cases of neonatal deaths. Infections of all kinds were responsible for 30.7 per cent of all deaths, and for 65.5 per cent of the 241 deaths which took place after the third day of life. In a personal communication (1947), she states that there were eight cases of suppurative meningitis during the five-year period of her review (1939-43), a percentage of 1.3 of the total deaths.

Six further cases of suppurative meningitis, all of them caused by coliform bacilli, are reported below.

\section{Case Histories}

\section{CASE 1}

The mother was a 10-para, aged 40 years. Labour was induced by rupture of the membranes on Oct. 18, 1946 , and pains began early on the next day. She had no previous history of any infection of the birth canal or urinary tract. The patient was distressed during the first stage, and after twenty-one hours her pulse rate was 140 per minute and temperature $104^{\circ} \mathrm{F}$. Foetal heart rate at this time was 150 per minute. The pyrexia subsided within three hours and did not recur.
The child was delivered after a first and second stage lasting thirty-eight hours. The infant was a male and weighed $7 \mathrm{lb}$. $14 \mathrm{oz}$. At that time it was cyanotic for a few minutes only. Following this nothing abnormal was noticed until he was put to the breast for the first time after birth, when 7 hours old. He would not suck, and there was a sudden onset of nystagmus and some twitching of the limbs. The child remained restless, vomited several times, and 13 hours after birth had the first of numerous convulsions. Death ofcurred 16 hours 40 minutes after delivery.

Post-mortem examination.-The body was that of a full-term child showing early evidence of dehydration. There were no external marks.

Respiratory system.-There was some mucus in the upper air passages. Sub-pleural petechial haemorrhages were seen over both lungs, and on section the organs themselves were atelectatic, showing only small areas of expansion.

Central nervous system.-The skull was normal. The dura did not bulge, and there was no tear of tentorium or falx. In the subarachnoid space there was a considerable amount of thick, greenish pus, particularly over the base of the brain, from where it tracked along the superficial cerebral veins to the superior surface of the hemispheres. There was no excess of cerebrospinal fluid and no internal hydrocephalus. On section the cerebral hemispheres, midbrain, cerebellum, and medulla were normal. Basal arteries, mastoid air-cells, and venous sinuses were normal. Examination of cardiovascular, alimentary, hepatic, genito-urinary, and endocrine systems revealed no abnormality.

Bacteriology.-Films of pus from the subarachnoid space showed many polymorphs and Gram-negative bacilli, some of which were intracellular. Cultures yielded a heavy growth of motile coliforms, giving the biochemical reactions of Bact. coli communis.

Histology.-The lung showed severe atelectasis of foetal type.

Various sections of the brain show acute purulent meningitis, with the majority of the cellular exudate made up of lymphocytes and other mononuclear cells, the number of polymorphs being small. Gram films show many Gram-negative bacilli in the exudate. 


\section{CAse 2}

The mother was a 2-para, labour being surgically induced on Dec. 16, 1946, as it was several weeks overdue. The labour was normal, and the child, a male, was delivered on Dec. 18. His weight was $6 \mathrm{lb}$. $12 \mathrm{oz}$., and for the first few days his condition was satisfactory, although he did not feed well and was of a poor colour. On the sixth day there was a sudden increase of temperature to $102^{\circ} \mathrm{F}$. and marked increase of respirations. On the following day he developed twitching movements of limbs, on several occasions amounting to convulsions. Neck rigidity was present, and Kernig's sign positive. A diagnosis of meningitis was made, but before any further steps could be taken the child lapsed into coma, dying on Dec. 26, 1946.

Post-mortem examination.-The body was that of a well developed male infant showing slight cyanosis but no other external abnormalities.

Central nervous system.-The skull was normal. The dura was normal, with no tears of falx or tentorium. The brain showed severe flattening of the convolutions, and a diffuse purulent exudate was present in the subarachnoid space. At the base of the brain this exudate was yellow and opaque. The basal arteries, venous sinuses, and mastoid air-cells were normal. Cerebral hemispheres, mid-brain, cerebellum, and medulla were normal on section. Apart from some patchy atelectasis of both lungs, examination of respiratory, alimentary, hepatic, genito-urinary, and endocrine systems revealed no abnormalities.

Histology.-Section of the brain showed a purulent exudate in the subarachnoid space of similar cytology to that in Case 1 , with predominance of lymphocytes (Plate $\mathrm{I} a$ ). Gram film of this section shows numerous Gram-negative bacilli, many of them intracellular and morphologically similar to Bact. coli. Unfortunately, no cultures were made from this specimen, but the finding of Gram-negative bacilli morphologically similar to Bact. coli and unaccompanied by any other bacteria suggests that they are the responsible organisms and that the condition is a coliform meningitis.

\section{CAse 3}

Mrs. P., a multipara, was delivered at her home of a full-term male child on Nov. 4,1946 , the birth weight being $6 \mathrm{lb}$. 2 oz. The antenatal period and labour had been normal. The infant was breast-fed for two days, but sucked badly and was put on to artificial feeds. The child was still feeding very poorly on Nov. 10, and as it appeared to be getting weaker was admitted to hospital. On examination he was drowsy and cold ; there was some cyanosis and signs of early dehydration. He vomited soon after admission. On Nov. 12 no abnormalities could be detected on examination, except for a possible weakness of the right arm, and he was still not feeding well. On Nov. 14 he was feeding better, but the skin was dry and inelastic, suggesting dehydration, but the fontanelle was not depressed. On Nov. 16 the pulse rate dropped from 150 on admission to below 100 per minute. Temperature still remained subnormal and the fontanelle tension was normal although general signs of dehydration were marked. There was, however, some separation of the cranial sutures. No neck rigidity was detected. On Nov. 17, 1946, the child was moribund and refusing all feeds. The fontanelle pressure was now increased, but there was still no neck rigidity. The pulse rate dropped to 64 per minute and death occurred on Nov. 18, 1946.

Post-mortem examination.-The body was that of a dehydrated male infant.

Respiratory system.-The upper air passages showed acute inflammatory changes, and the pleural cavities contained $15 \mathrm{c.cm}$. of straw-coloured effusion. On section the bases of both lungs showed a patchy pneumonic consolidation, and there were some areas of lung which had not fully expanded.

Central nervous system.-The skull was normal. The dura was bulging, and there was marked engorgement of the leptomeninges, with a thin sero-purulent exudate in the subarachnoid space, particularly marked at the base of the brain. The venous sinuses, basal arteries, and mastoid air-cells were normal.' The brain was oedematous on section, but otherwise normal throughout.

Examination of cardiovascular, alimentary, hepatic, genito-urinary, and endocrine systems revealed no abnormality.

Bacteriology.-Films made from the subarachnoid space at necropsy showed numerous Gram-negative bacilli and pus cells. Cultures yielded heavy growths of coliforms giving the biochemical reactions of Bact. coli communis.

Histology.-Sections of the brain showed an acute purulent leptomeningitis with a considerable amount of haemorrhage amongst the exudate, and a cytology predominantly lymphocytic in character.

Sections of lung showed acute bronchopneumonic congestion and some collapse.

Cases 4 and 5 are siblings and two of quadruplets. As the hospital was bombed soon after their death the clinical notes were destroyed, and the histories are, therefore, lacking in detail.

\section{Case 4}

L. was the first delivered of quadruplets born prematurely on June 3, 1944, with a birth weight of $3 \mathrm{lb}$. $9 \mathrm{oz}$. She appeared well until the seventh day, when there was a sudden rise of temperature to $102^{\circ} \mathrm{F}$. with the development of gradual abdominal distension and jaundice during the succeeding days. Cerebral screaming attacks also occurred. The blood count showed a mild leucocytosis of 25,000 cells per c.mm. During the performance of the differential count, which was normal, a macrophage (Plate $\mathrm{I} b$ ) containing what appeared to be ingested bacteria was seen; 
this suggested the presence of septicaemia, as did the continued fever and gradually increasing jaundice before death, on June 19, 1944, at the age of 16 days.

Post-mortem examination.-The body was that of a small and premature female infant. The skin and all internal structures were deeply jaundiced.

Central nervous system.-The skull and dura were normal. Acute inflammatory changes were present in the leptomeninges with thin yellowish pus over the vertex and superior aspect of the cerebellum. There was also exudate over most of the basal cisterns. The cerebrospinal fluid in the ventricles was frankly purulent. The basal arteries, venous sinuses, and mastoid air-cells were normal. Sections of the brain were normal throughout. Examination of all the other systems revealed no abnormality.

Bacteriology.-Swabs taken from the brain and ventricles at post mortem showed large numbers of pus cells and Gram-negative bacilli in the stained films. Cultures yielded a pure growth of motile coliforms.

Histology.-Sections of the cerebral cortex showed acute inflammatory changes, but unfortunately the meninges from this specimen were lost.

Sections of the liver showed exudation of bile pigment, congestion, and fatty change.

\section{CASE 5}

D. was born prematurely on June 3,1944 , the second to be delivered with a birth weight of $3 \mathrm{lb} .13 \mathrm{oz}$. His condition was satisfactory for the first few days, but he began to feed poorly at about the fourth day and when six days old developed a sudden rise of temperature. A day or so later there was onset of cerebral screaming attacks with gross abdominal distension. Treatment was begun with sulphathiazole by mouth, but there was gradual deterioration until death on June 14, 1944, when the child was 11 days old.

Post-mortem examination.-The body was that of a small premature infant showing some abdominal distension and generalized jaundice of the skin and internal structures.

Central nervous system.-The skull and dura were normal. The subarachnoid space contained a purulent exudate that was particularly thick over the vertex, superior aspect of the cerebellum, and tips of the temporal lobes. The cerebrospinal fluid was cloudy but not frankly purulent. Venous sinuses and basal arteries were normal. The right mastoid air-cells contained a little pus, but those on the left were normal. Examination of the cardiovascular, respiratory, alimentary, hepatic, genito-urinary, and endocrine systems revealed only scattered sub-serosal petechial haemorrhages.

Bacteriology.-Films from ventricular fluid, right mastoid, and subarachnoid space showed numerous pus cells and many Gram-negative bacilli. Cultures all yielded a heavy growth of Bact. coli communis. Culture from the left mastoid yielded only a few colonies of Staph. albus.
Histology.-There was acute purulent leptomeningitis of the brain, the underlying brain showing some congestion.

Sections of liver showed fatty change, exudation of bile pigment, and some areas of focal necrosis.

\section{CASE 6}

The male infant was born by normal labour on April 29, 1947. The child appeared well until it was 3 days old, when it suddenly became grey, with difficult and distressed breathing. The birth weight was $8 \mathrm{lb}$. $3 \mathrm{oz}$., and at the onset of symptoms had fallen to $8 \mathrm{lb}$. $1 \mathrm{oz}$. Later the same day the temperature suddenly rose to $103^{\circ} \mathrm{F}$. with grunting respiration. The infant had repeated atttacks of spasm of the hand muscles, similar to tetani. There was no neck rigidity and the pulse was then uncountable. He was given oxygen and chloral, the temperature fell to $102.4^{\circ} \mathrm{F}$. at 6 a.m. on May 3, but rose suddenly to $105.6^{\circ} \mathrm{F}$. at 10 a.m. a quarter of an hour before death.

Post-mortem examination.-The body was that of a well-developed male infant. There was moderate cyanosis of mouth and finger tips, but no dehydration or jaundice.

Respiratory system.-The upper air passages contained a large quantity of purulent material and both lungs showed on section a generalized bronchopneumonia. The pleural surfaces were normal.

Central nervous system.-The skull was normal. The dura was normal, with no tear of falx or tentorium. A greenish exudate which had a faecal odour was present in the subarachnoid space. It covered the base of the brain and tracked to the vertex. There was no excess of fluid in the ventricular system. There were no flattening of the convolutions, and the brain was normal throughout on section. The basal arteries, venous sinuses, and mastoid air-cells were normal.

Bacteriology.-Swabs of the subarachnoid space showed numerous Gram-negative bacilli and pus cells. Cultures yielded a heavy and pure growth of Bact. coli communis. This organism was not inhibited by 75 units per ml. of penicillin but was by 100 units of penicillin. Swabs from lung showed numerous Gram-negative cocci and some Gram-positive bacilli. Cultures yielded a good growth of Bact. coli communis and a few colonies of Staph. albus. The coliform in this culture showed similar results to penicillin sensitivity tests as did that isolated from the brain.

Histology.-Sections of the brain showed a purulent leptomeningitis.

\section{Discussion}

Incidence.-The age at death in Cruickshank's (1930) series of suppurative meningitis cases varied from 2 to 17 days, 88 per cent of the infants dying between the fifth and thirteenth day.

In Levinson's (1945) group of 'cases there were eight under one month, and five of these were in infants 14 days old or less; the youngest was 3 


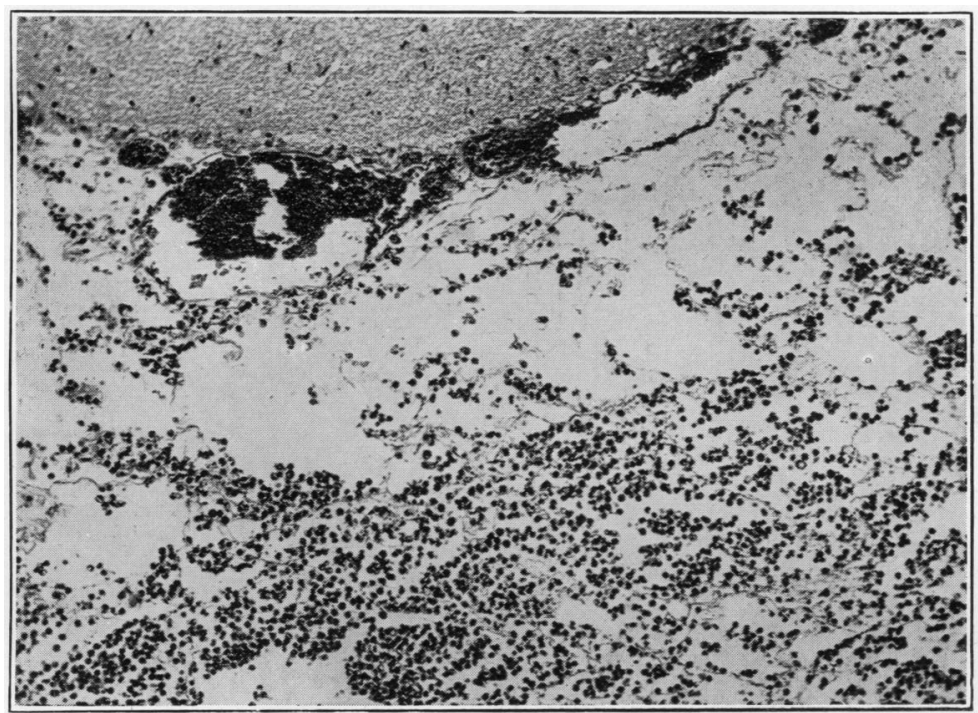

(a).- Section of the brain in Case 2, showing a purulent exudate in the subarachnoid space, with predominance of lymphocytes.

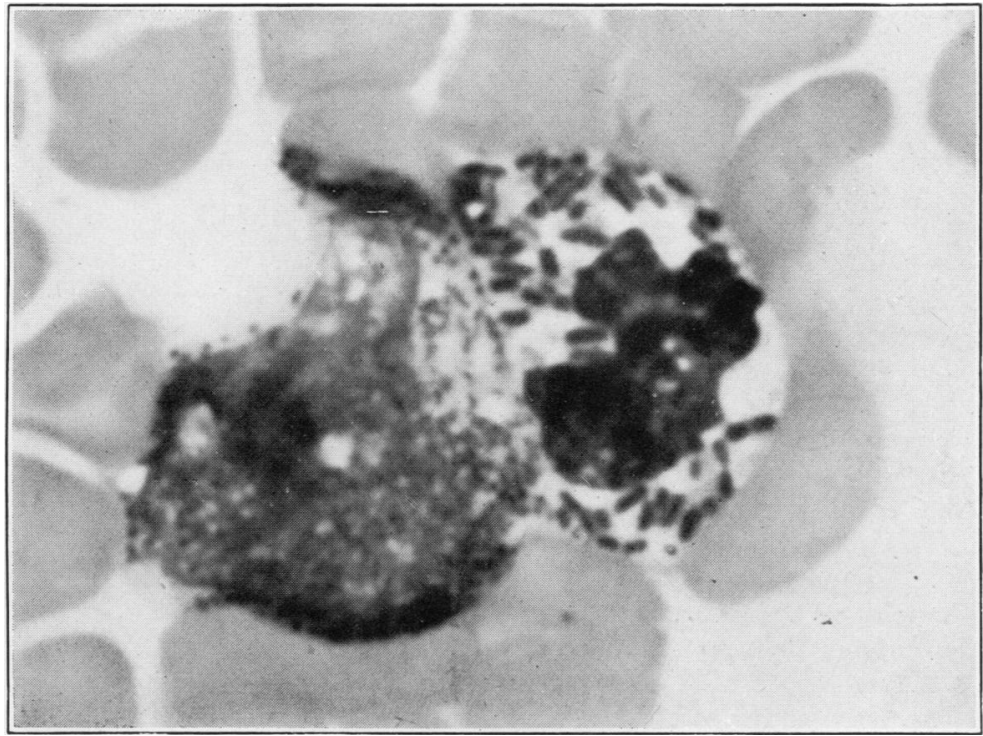

(h).-Macrophage containing what appear to be ingested bacteria, Case 4 .

Plate I

L 
days, and the eldest 21 days. MacGregor's cases were all under 3 weeks, the ages at death being 16 , $9,9,7,5$, and 4 days in the uncomplicated cases. In two others death occurred at 10 days and 6 hours respectively, following an infection of a meningocele in spina bifida.

In the present series, all were cases of primary meningitis except possibly Case 4 , where infection of the mastoid air-cells may have preceded the meningitis. All deaths oscurred under 3 weeks of age, at 17 hours, $8,14,11,16$, and 4 days. Case 1 is of particular interest, as there does not appear to be any previous record in the literature of a death from primary suppurative meningitis occurring less than 24 hours after delivery. In this incidence infection most probably occurred in utero at the time labour was induced.

Both Craig (1936) and Cruickshank state that infants developing meningitis are often premature. Two of the present cases were born prematurely. They were from a family of quadruplets, and it is well recognized that such infants born in multiple pregnancies possess a lower resistance to infection than those born at full term and of a single pregnancy. Of the two remaining children in this family, one, who had a rise of temperature during the second week of life, died of hydrocephalus at the age of 6 months. This condition may well have been secondary to unrecognized meningitis in the neonatal period, although no necropsy was performed to confirm it. The fourth child is alive and well and now 3 years old.

Symptomatology and diagnosis.-During the newborn period and in early infancy meningitis presents few, if any, symptoms which are referable to the local condition. The onset may be sudden or gradual. The temperature frequently remains normal, as was the case in 25 per cent of Levinson's series. However, a sudden rise of temperature may be an early sign, and this was observed in four of the six cases here reported. Other early signs are failure to feed and restlessness (three cases) and twitching of limbs or muscular spasms (three cases). Neck rigidity is not common and was only observed in Case 2. Convulsions frequentiy occur before death, and a cephalic cry may develop. Bulging of the fontanelle was observed in only one case, although Levinson states that it is nearly always present. All these signs are suggestive of an intracranial lesion or at any rate cerebral anoxia, which may also be produced by atelectasis, neonatal pneumonia, septicaemia, and neonatal tetani. Under these circumstances it is important that immediate examination of the cerebrospinal fluid following lumbar puncture should be performed. This will confirm or deny any suspicion of the possibility of an intracranial lesion being present. It will also enable a differential diagnosis to be made as between meningitis and intracranial subdural haemorrhage.

In addition, Fothergill and Sweet (1933), having isolated the organism from the blood as well as the cerebrospinal fluid in 88 per cent of cases occurring in infants between 1 and 5 weeks old, state that bacteriaemia is very common in this type of meningitis. In this series the occurrence of bacilli in the blood was demonstrated in Case 4, where a macrophage containing ingested bacteria was seen in blood film (Plate $\mathrm{I} b$ ).

Bacteriology.-It is probable that in all the six cases outlined above the responsible organism was Bact. coli, and a certain bacteriological diagnosis was made in five of them, as it is extremely unlikely that the presence of coliforms isolated was due to post-mortem infection of tissues. There have been two reviews where the bacteriology of neonatal meningitis has been classified-that of Cruickshank (1930) and a later one of Flensborg (1942), which includes all cases in the literature at that time. To these should be added MacGregor's cases (see Table).

TABLE

ANALYSIS OF CASES OF NEONATAL MENINGITIS IN THE LITERATURE

\begin{tabular}{|c|c|c|c|}
\hline & $\begin{array}{c}\text { Cruickshank } \\
(1930)\end{array}$ & $\begin{array}{c}\text { Flensborg } \\
\text { (1942) }\end{array}$ & $\begin{array}{c}\text { MacGregor } \\
(1946)\end{array}$ \\
\hline $\begin{array}{l}\text { Bact. coli } \\
\text { Staph. . . } \\
\text { Strep. } \\
\text { Staph. + Strep. } \\
\text { Pneumococcus } \\
\text { H. influenzae .. } \\
\text { N. catarrhalis .. } \\
\text { Gonococcus .. } \\
\text { Mixed flora .. } \\
\text { Ps. pyocyaneus }\end{array}$ & $\begin{array}{r}11 \\
1 \\
\frac{7}{3} \\
- \\
- \\
-\end{array}$ & $\begin{array}{r}68 \\
9 \\
23 \\
7 \\
12 \\
4 \\
1 \\
1 \\
4 \\
\end{array}$ & $\begin{array}{l}6 \\
- \\
- \\
- \\
- \\
-\end{array}$ \\
\hline
\end{tabular}

In contrast Neal (1926) reviewed fifty cases of meningitis occurring in children over three weeks and under three months of age. The incidence of the various organisms in thirty-five cases where bacteriological diagnosis was made was as follows:

$\begin{array}{lr}N . \text { meningococcus : } & 24 \text { cases } \\ M \text {. Tuberculosis : } & 5 \text { cases } \\ \text { Pneumococcus : } & 3 \text { cases } \\ \text { Bact. coli : } & 3 \text { cases }\end{array}$

From the findings in all these reviews, coliforms are clearly the commonest pathogen in neonatal 
meningitis. However, its incidence decreases with age and it is rarely found over two years, when meningococcal meningitis is reaching its maximal incidence. Although the most susceptible age period for this infection is given from 0 to 5 years (Compton, 1918), it is unusual in the first three months of life (Topley and Wilson, 1946). A possible reason for its low incidence may be found in the possession of a congenital immunity which lasts only for a few months. The restricted age incidence of coliform meningitis is not easily explained, but some light may be thrown on this point by a study of specific agglutinins present, in the sera of children at birth, to these and similar organisms.

Ravid (1935) says that " in the blood of foetuses and the newborn agglutinins to B. coli are absent," but he presents no evidence to substantiate this statement. Flensborg in his review also states that the newborn lack normal coli agglutinins present in adults.

Recently Wright (1947) has studied the transmission of coli agglutinins across the placenta, using seven different suspensions of coliforms obtained from " pathological" lesions. She found: (1) that the titres of both " $\mathrm{O}$ " and " $\mathrm{H}$ " agglutinins in the mother's serum at the time of delivery corresponded closely to that in the cord blood of the infant ; (2) that of 55 mothers and babies examined, practically none possessed agglutinins to all the seven suspensions, and one or two no agglutinins at all. Most of the subjects possessed recognizable agglutinins to about half the suspensions used.

From her results it seems likely that nearly every infant is vulnerable to any strain of coliform for which little or no agglutinins are present, and that chance contacts with such strains may result in infection. This susceptibility, together with the well recognized feebleness of antibody production during the early months of life, may explain the high incidence of coliform meningitis at this age.

Pathology.-The pathological changes in these cases differ little from those seen in other types of suppurative meningitis except for the predominance of lymphocytes and mononuclear cells in the exudate. In most of the infants the meningitis probably followed bacteriaemia. The portal of entry of the responsible organisms is, however, uncertain clinically, and the post-mortem findings give no further assistance in locating the site of primary infection.

Treatment.-Barrett and others (1942) say that the mortality without chemotherapy is 80 per cent, and none of the cases in the present series recovered. They review six cases in which sulphonamides were used. There was only one death in the acute phase, although at least one other appeared to have died later from hydrocephalus. They say that sulphathiazole was then the drug of choice.

Since then, Pearlman and Bell (1944) have recorded a death in neonatal meningitis following adequate treatment with various sulphonamides in a newborn child, and Kohlbry (1942) a recovery in a male child aged 7 days treated with sulphapyridine. In an older patient Alexander (1946) treated successfully a coli meningitis following extensive fractures and osteitis of the right tibia (male, aged 19 years), with streptomycin.

As the organism in Case 6 was sensitive to 100 units per ml. of penicillin, yet another possible line of treatment was opened up by giving a large dose of the drug intrathecally.

However, the number of treated cases is still very small and it is hoped that, with earlier diagnosis in the future, these methods of chemotherapy may be more fully tested.

\section{Summary}

The literature on neonatal meningitis is reviewed and a series of six fatal cases described.

The aetiology, symptomatology, and bacteriology are discussed, views being presented to explain the predominance of coliforms as the responsible pathogen. Possible lines of treatment are discussed.

My thanks are due to Prof. G. Payling Wright and Dr. Philip Evans for helpful criticism in the preparation of this paper, to members of the clinical and pathological staff of Lewisham L.C.C. Hospital for help with notes of three of the cases, and to R. S. Morgan for the photomicrographs.

\section{REFERENCES}

Alexander, A. J. (1946). J. Amer. med. Ass., 131, 663. Barrett, G. S., et al. (1942). Amer. J. Dis. Child., 63, 41. Barron, M. (1918). Amer. J. med. Sci., 156, 358.

Compton, A. (1918). J. R. Army med. Cps, 31, 241.

Compton, A. (1918). J. R. Army med. Cps, 31
Craig, W. S. (1936). Arch. Dis. Childh., 11, 171.

Cruickshank, J. N. (1930). Spec. Rep. Ser. med. Res. Coun., Lond., No. 145 .

Flensborg, E. W. (1942). Acta. pediátr. esp., 30, 305.

Fothergill, L. D., and Sweet, L. K. (1933). J. Pediat., 2, 696.

Kohlbry, C. O. (1942). Minnesota Med., 25, 200.

Levinson, A. (1945). Brennemann's “Practice of Pediatrics," Vol. IV, Ch. 8, p. 25. W. F. Prior Co. Inc.

MacGregor, Agnes $\mathbf{R}$. (1946). Brit. med. Bull., 4, 174

MacGregor, Agnes R. (1946). Brit. med. Bull., 4,
Neal, J. B. (1926). Amer. J. med. Sci., 172, 740.

Pearlman, L. N., and Beli, R. G. (1944). Arch. Pediat., 61, 75

Ravid, J. M. (1935). Amer. J. Dis. Child., 49, 1282.

Topley, W. W. G., and Wilson, G. S. (1946). "Principles of Bacteriology and Immunology," Vol. II, p. 1433. Arnold, London.

Wright, Helen Payling (1947). Personal communication. 


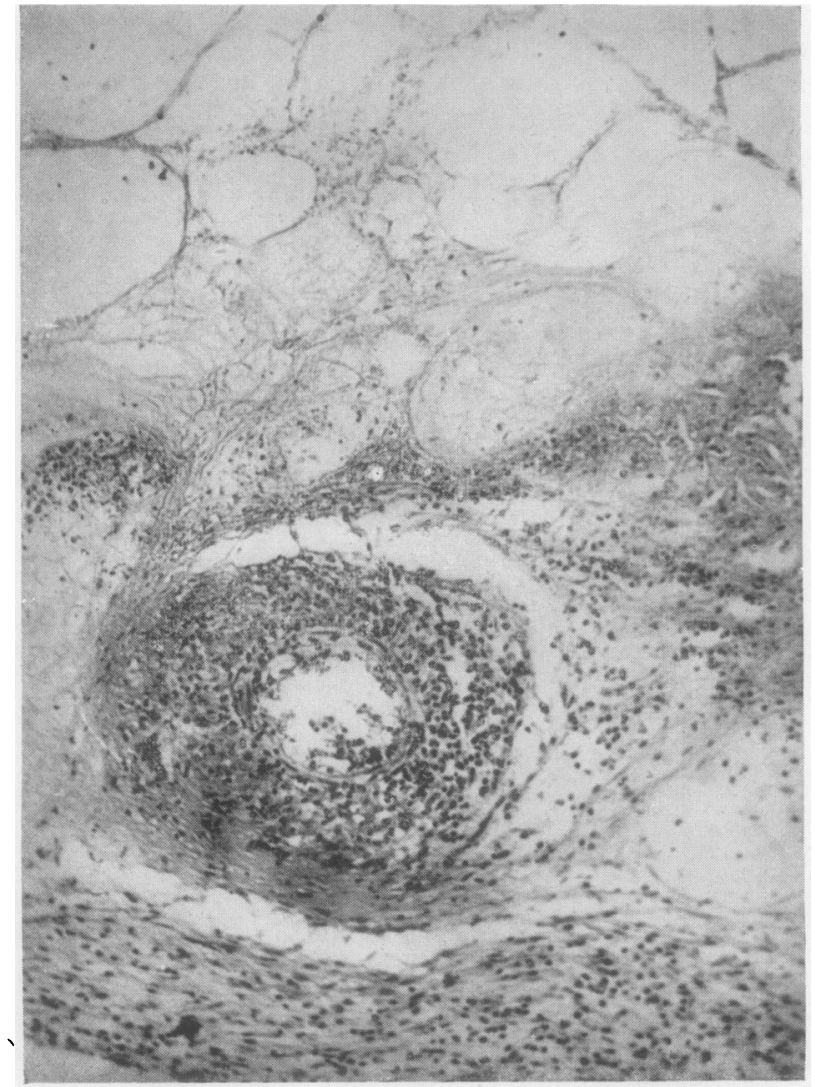

(a).-Section through the spinal meninges of $\vec{\omega}$ a case of tuberculous meningitis, show- $\vec{F}$ of the picture

(b).-Areas of clearance of test organism produced by streptomycin plus heparin (C) and streptomycin alone (B). No clearance round heparin alone (A).

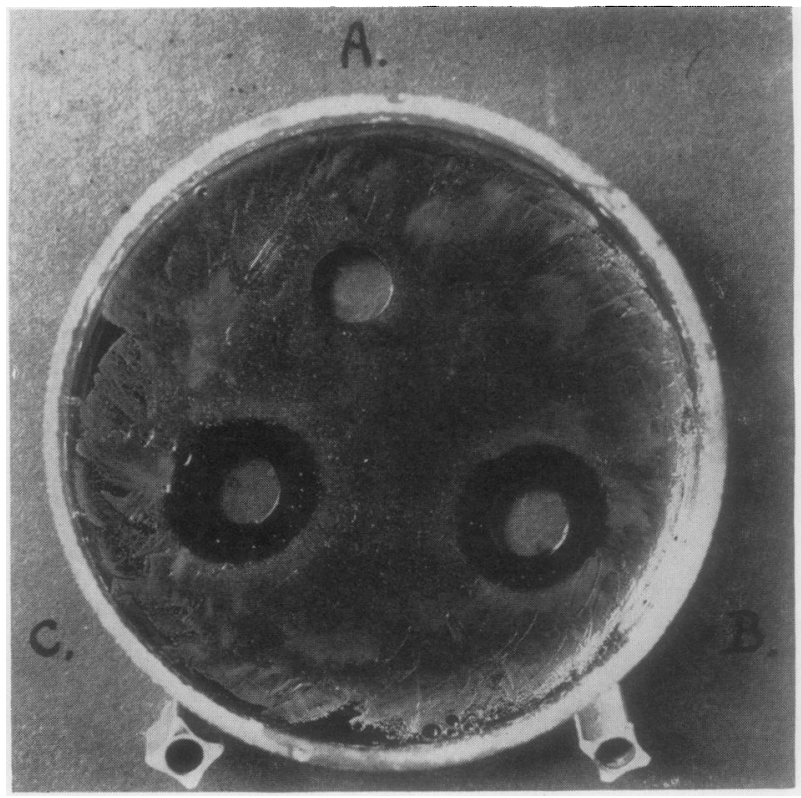

